\title{
Anaesthetic considerations in gastroschisis repair at a tertiary care hospital
}

\author{
Raksha Kundal ${ }^{1}$, Neelam Dogra ${ }^{2 *}$, Vijay Kumar Kundal ${ }^{3}$ \\ Associate Professor ${ }^{l}$, Department of Anaesthesia, Lady Harding Medical College, Delhi, India. Senior \\ Professor 2*, Department of Anaesthesia, SMS Medical College, Jaipur, India. Associate Professor ${ }^{3}$, \\ Department of Paediatric Surgery, Ram Manohar Lohiya Hospital, Delhi, India.
}

\begin{abstract}
Gastroschisis is congenital anomaly characterized by a defect in the anterior abdominal wall with evisceration of abdominal contents. Choice of anaesthesia for its repair varies from conventional general anaesthesia with opioids for analgesia, general anaesthesia along with regional techniques like spinal and caudal blocks or sole regional anaesthesia.
\end{abstract}

\begin{abstract}
Aims: To retrospectively analyze various techniques used for anaesthetic management of gastroschisis repair surgery in our institute and compare outcome of patients in terms of extubation time and requirement of postoperative mechanical ventilation.
\end{abstract}

Material and Methods: Eighty-two cases operated for gastroschisis in our hospital over a period of four years were retrospectively analyzed in terms of age, sex, gestation, type of surgical procedure and anaesthesia techniques. Time of extubation and requirement of postoperative mechanical ventilation was compared between general anaesthesia and regional anesthesia group.

Results: Seventy-two cases were included in study with 28 patients in general anaesthesia group and 44 patients in regional group. Out of 14 term neonates 2 needed post-operative ventilation in regional group. 6 out of 10 term neonates needed postoperative ventilation in opioid group. Among preterm neonates 12 out of 30 needed post-operative ventilation in regional group and all 18 needed postoperative ventilation in opioid group. In both term as well as preterm patients, regional group had faster extubation rate and lesser need of postoperative ventilation when compared to general anaesthesia group. Difference was statistically significant.

Conclusion: We conclude that use of regional blocks along with general anaesthesia is safe and effective for management of neonates with gastroschisis presenting for primary repair.

Keywords: gastroschisis repair; anaesthesia; neonatal emergency; regional anaesthesia; neonate

\section{Introduction}

Gastroschisis is a congenital anomaly in which there is a defect of abdominal wall and evisceration of abdominal contents which include small and large intestine and occasionally spleen and liver. Defect is usually 2 to $5 \mathrm{~cm}$ and is more common on

*Correspondence: Neelam Dogra

E mail: neelam_dogra24@yahoo.com

https://orcid.org/0000-0002-5729-3348

Received: $13 / 01 / 2019$

Accepted: 01/06/2019

DOI: http://doi.org/10.4038/slja.v27i2.8402

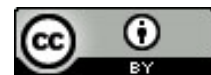

right side of umbilical cord and it lacks peritoneal cover with normal and properly placed umbilicus. ${ }^{1,2}$ Its incidence is 1 in 2000 with male preponderance.

Surgical management of gastroschisis includes primary surgical closure of abdominal wall and staged closure, in which silo (silastic or teflon mesh) is used to close the defect. ${ }^{3}$

Another approach is use of spring-loaded silo in NICU or in delivery room where slow reduction of extra abdominal content is done followed by prosthesis removal and closure of defect under anaesthesia. $^{4}$

Choice of anaesthesia varies from conventional general anaesthesia with opioids for analgesia, general anaesthesia along with regional techniques 
like spinal and caudal blocks. Other options are use of spinal block or combined spinal epidural alone. ${ }^{5,6}$

Successful anaesthetic management of such patients require anticipation of associated problems which include prematurity, hypothermia and dehydration due to large exposed bowel surface area and sepsis. Advances in anaesthesia and neonatology have greatly improved survival of these neonates. Increased rate of prenatal diagnosis and hospital deliveries have resulted in improved anaesthetic and surgical management of these patients. General anaesthesia consists of endotracheal intubation with controlled ventilation. Muscle relaxants should be used for optimum closure of defect. In recent times regional blocks are used in management of such patients with general anaesthesia. The primary aim of this study was to retrospectively analyze various techniques used for anaesthetic management of gastroschisis repair in our institute and to compare outcome of patients in term of extubation time and duration of ventilation in general anaesthesia technique and with regional blocks alone or as adjuvant to general anaesthesia.

\section{Materials and method}

A retrospective analysis of all the gastroschisis cases operated from year 2013 to 2016 was carried out. A total of 82 cases were operated in these 4 years and data was collected from case sheets of the patients from hospital records and was analyzed in terms of demography, gestation, type of surgical procedure and anaesthesia technique.

Patients with sepsis and on preoperative oxygen support due to varying reasons were excluded.

A total of 72 patients were included in study, ten neonates were excluded of which six were on ventilator support and four had sepsis. Various anaesthesia techniques practiced in our institute were analyzed and comparison between general anaesthesia (GA) only (opioid group) and GA with regional anesthesia (RA)techniques or RA alone (regional group) was done in terms of requirement of postoperative mechanical ventilation and time to extubation in operated neonates.
We also considered factors which may influence requirement of postoperative ventilation like gestational age, primary closure or use of silastic pouch and analgesics.

\section{Statistical analysis}

Data collected is summarized in tables. Statistical analysis was done by using (SPSS, Inc, Chicago, IL, USA) Program version 16. Mann Whitney, student $t$ test and Fisher' exact for quantitative variables and Chi square test is used for finding association between two categorical variables.

\section{Results}

Evaluation of demographic data shows that male patients $(n=52) 72.2 \%$ presenting for gastroschisis surgery were more than females $(n=20) 27.7 \%$ (Table 1).

Table 1: Demographic data

\begin{tabular}{|l|l|}
\hline Gender & $\mathbf{n}=\mathbf{7 2}$ \\
\hline Male & $52(72.2 \%)$ \\
\hline Female & $20(27.77 \%)$ \\
\hline Gestation & \\
\hline Term & $24(33.3 \%)$ \\
\hline Preterm & $48(66.6 \%)$ \\
\hline
\end{tabular}

Mean weight of patients was $2.45 \mathrm{~kg}$ in regional group and $2.30 \mathrm{~kg}$ in opioid group, weight was comparable and had no significant difference. Primary closure of defect was done in 46 neonates whereas in 26 neonates silastic pouch was used. 28 neonates received general anaesthesia with opioids for analgesia, twenty received general anaesthesia along with caudal block, twenty-one received general anaesthesia along with spinal block rest, three received spinal anaesthesia only. (Table 2) 
Table 2: Surgical and anaesthesia technique

\begin{tabular}{|l|l|}
\hline Surgical techniques & $\mathbf{n = 7 2}$ \\
\hline Primary closure & $46(63.8 \%)$ \\
\hline Silastic pouch & $26(36.1 \%)$ \\
\hline Anaesthesia techniques & $\mathbf{n = 7 2}$ \\
\hline $\begin{array}{l}\text { General anaesthesia plus opioid } \\
\text { analgesia }\end{array}$ & $28(38.8 \%)$ \\
\hline $\begin{array}{l}\text { General anaesthesia (without muscle } \\
\text { relaxant and opioids) plus spinal } \\
\text { anaesthesia }\end{array}$ & $21(29.1 \%)$ \\
\hline General anaesthesia plus caudal & $20(27.1 \%)$ \\
\hline Spinal anaesthesia only & $3(4.1 \%)$ \\
\hline
\end{tabular}

Both term as well as preterm neonates of regional group had lesser need of postoperative ventilation and difference was statistically significant.

Among term neonates 2 of14 and 6 out of 10required postoperative mechanical ventilation in regional group and GA with opioid group respectively.

Among preterm neonates 12 out of 30 needed postoperative ventilation in regional group and all 18 patients needed postoperative ventilation in opioid group.

Both term as well as preterm patients had early extubation in the regional group and difference was statistically significant.

Mean time of extubation in term neonates was 1 hour in regional group and $3 \mathrm{hrs} 40 \mathrm{mins}$ in opioid group, whereas in preterm neonates it was $6 \mathrm{hrs}$ $20 \mathrm{mins}$ in regional group and $41 \mathrm{hrs}$ in opioid group. (Table 3)

The results of our study showed that premature neonates needed postoperative ventilation for longer duration as compared to term neonates. Extubation was earlier in regional group in both term as well as preterm neonates. All other factors were comparable.

\section{Discussion}

Choice of anesthesia varies from conventional general anesthesia with opioids for analgesia, general anesthesia along with regional techniques like spinal block and combined spinal epidural catheters as sole anesthesia technique and use of caudal block only. ${ }^{7,8}$

Table 3: Comparison of demographic data, ventilation and hours of extubation

\begin{tabular}{|c|c|c|c|}
\hline & $\begin{array}{l}\text { Regional } \\
\text { Group } \\
(\mathrm{N}=44)\end{array}$ & $\begin{array}{l}\text { Opioid } \\
\text { Group } \\
(\mathrm{N}=28)\end{array}$ & P VALUE \\
\hline $\begin{array}{l}\text { Gestational age } \\
\text { (weeks) }\end{array}$ & $36.03+5.5$ & $35.14 \pm 7.5$ & $\begin{array}{l}0.56 \\
\text { (t test) }\end{array}$ \\
\hline Weight in $\mathrm{kg}$ & $\begin{array}{l}2.45+0.45 \\
(1.4-3.2)\end{array}$ & $\begin{array}{l}2.30+0.5 \\
(1.4-3.4)\end{array}$ & $\begin{array}{l}0.191 \\
(\mathrm{t} \text { test })\end{array}$ \\
\hline $\begin{array}{l}\text { Term neonate } \\
\text { requiring post- } \\
\text { operative } \\
\text { ventilation }\end{array}$ & $2 / 14$ & $6 / 10$ & $\begin{array}{l}0.019 \\
\text { (chi-square) }\end{array}$ \\
\hline $\begin{array}{l}\text { Preterm } \\
\text { neonates } \\
\text { requiring } \\
\text { postoperative } \\
\text { ventilation }\end{array}$ & $12 / 30$ & $18 / 18$ & $\begin{array}{l}<0.001 \\
\text { (Fisher's } \\
\text { exact) }\end{array}$ \\
\hline $\begin{array}{l}\text { Mean time to } \\
\text { extubation in } \\
\text { term neonates }\end{array}$ & $\begin{array}{l}1 \mathrm{hr}+0.95 \\
(0.20-4 \mathrm{hr})\end{array}$ & $\begin{array}{l}3.40 \\
\mathrm{hr}+1.25 \\
(1-6 \mathrm{hr})\end{array}$ & $\begin{array}{l}<0.001 \\
(\mathrm{t} \text { test })\end{array}$ \\
\hline $\begin{array}{l}\text { Mean time to } \\
\text { extubation in } \\
\text { preterm } \\
\text { neonates(mean) }\end{array}$ & $\begin{array}{l}6.20 \mathrm{hr}+2.75 \\
(3-14 \mathrm{hr})\end{array}$ & $\begin{array}{l}41 \mathrm{hr}+16.0 \\
(10-74 \mathrm{hr})\end{array}$ & $\begin{array}{l}<0.001 \\
(\mathrm{t} \text { test })\end{array}$ \\
\hline
\end{tabular}

The result of study shows that time of intubation and need of postoperative ventilation is reduced in GA with regional blocks for analgesia as compared to GA with opioids and difference is statistically significant and our results were comparable with Murali Raghavan et al in 2008 they reviewed anesthetic management of gastroschisis and according to them traditional opioid analgesia when compared with regional technique may be associated with increased need for postoperative ventilation and general anesthesia without opioid and regional technique for analgesia is valid method for gastroschisis surgery. ${ }^{9}$

Techniques practiced in our institute for gastroschisis repair are GA with opioids for analgesia, GA along with caudal block, spinal anesthesia only and our modified technique of general anesthesia in which neonates are intubated after deepening anesthesia with sevoflurane. Muscle relaxants and opioids are altogether avoided, and spinal block is used for surgical anesthesia and analgesia. Benefit of this technique 
is that airway remains protected and side effects of opioids like postoperative apnoea are avoided. ${ }^{10}$ we avoid non-depolarizing neuromuscular agents as neonates have increased sensitivity due to reduced release of Ach from immature motor nerves. ${ }^{11}$ This technique results in early extubation of neonates. Our techniques matched with techniques used by other authors. ${ }^{5,8,9}$

In neonates the organs are immature, so drugs that depend on hepatic clearance like sedatives, opioids, neuromuscular blocking agent have prolonged duration of action and need to be given in titration. By giving regional block along with GA we can avoid use of muscle relaxants and opioid. Also, for maintenance of anesthesia lesser concentration of inhalational agent is required, all of which have depressant action on respiratory system, at the same time we are securing airway therefore no risk of aspiration and whenever required ventilation can be assisted.

Respiratory parameters should be closely monitored after closure as increased intraabdominal pressure may compromise respiration. We can use respiratory pressure monitoring as indirect method of measuring intra-abdominal pressure. ${ }^{12,13}$ Another indirect method is to measure intravesical pressure and if pressure is $<20 \mathrm{mmH}_{2} \mathrm{O}$ patient can be extubated. ${ }^{14}$ If distress is present postoperative ventilation in NICU is recommended. We in our cases used these techniques to prevent tight closure of anterior abdominal wall.

Dennis W. Vane et al in 1994 published a case series in which they used spinal anesthesia as sole anesthesia technique in premature neonates undergoing operative repair of gastroschisis. ${ }^{5}$ They advocated that it is possible to ascertain scope of primary reduction using respiratory status of the patient in their technique. This technique often alleviates need for intubation but placing spinal in a moving neonate is technically difficult and risky. When sedation is used in such neonates there is always a risk of intraoperative apnoea and need for assisted ventilation, and there is a risk of aspiration as airway is not protected.

Mangesh Gore et al in 2009 conducted successful anesthetic management of gastroschisis under combined spinal epidural anesthesia (CSE) ${ }^{6} \mathrm{CSE}$ is a good choice for this surgery as spinal will provide good analgesia and relaxation for surgery and epidural catheter will provide postoperative analgesia. Opioids can be avoided in this technique with less risk of respiratory depression in postoperative period. There is risk of unprotected airway and technical expertise is required for this technique.

Neha Kasat et al in 2017 successfully used combination of $0.5 \%$ bupivacaine $(2 \mathrm{mg} / \mathrm{kg})$ and $2 \%$ lignocaine with adrenaline $(1: 200000) 7 \mathrm{mg} / \mathrm{kg}$ in caudal block as sole anesthetic technique. ${ }^{8}$ In this technique we can avoid opioids and decrease need for postoperative ventilation. It is technically easy, but apart from other problems there is risk of unprotected airway. There are many techniques practiced for such surgeries, but techniques associated with better outcome and having good safety profile should be practiced.

\section{Conclusion}

We conclude that use of regional blocks along with GA is a safe and effective technique of anesthesia for management of neonates with gastroschisis presenting for primary repair. Use of regional blocks and avoiding opioid analgesia was associated with early extubation of neonates. As our study is a retrospective study, more randomized controlled trials are needed to validate results of our study.

\section{References}

1. Howell KK et al Understanding gastroschisis: An abdominal wall defect. Neonatal Network.1998; 17:17-25.

2. Klein MD et al Congenital defect of the abdominal wall. Textbook of pediatric surgery 6th Ed phialdelphia: mosby Elsevier. 2006 (73):1157-71. https://doi.org/10.1016/B978-0-323-028424.50076-0

PMid:16820417 PMCid:PMC2077548

3. Kandamasay Y, Whitehall J, Gill A et al H. Surgical management of gastroschisis in North Queensland from 1988 to 2007. Paediatr and Child Health.2010; 46:40-44. https://doi.org/10.1111/j.1440-1754.2009.01615.x PMid:19943863

4. Fischer JD, Chun K Moores et al Gastroschisis: a simple technique for staged silo closure. J Pediatr Surg 1995; 30 (8) 1169- 1171. 
https://doi.org/10.1016/0022-3468(95)90014-4

5. Vane DW, Abajian JC, Hong AR. Spinal anesthesia for primary repair of gastroschisis: a new and safe technique for selected patients. J Paediatr Surg. 1994;29:1234-5. https://doi.org/10.1016/0022-3468(94)90810-9

6. Gore M, Joshi K et al. Combined Spinal Epidural Anesthesia for Gastroschisis Repair, Indian journal of Anesthesia 2009; 53(2):223-225.

7. K Jessica, Goeller, Bhalla T. Combined use of neuraxial and general anesthesia during major abdominal procedures in neonates and infants. Pediatric Anesthesia.2014; 24(6):553-560. https://doi.org/10.1111/pan.12384 PMid:24612266

8. Kasat N, Dave N et al Gastroschisis repair under caudal anesthesia: a series of three cases. Rev Bras Anestesiol. 2017;67(3):326-328. https://doi.org/10.1016/j.bjane.2016.07.006

9. R Murali, M James. 5 year review of anesthetic management of gastroschisis pediatric 2008;18(8) : 731-735. https://doi.org/10.1111/j.1460-9592.2008.02666.x PMid:18613932

10. M. Nieaters, F .Overdyk, T. Smith et al opiod induced respiratory depression in pediatrics a review of case reports British journal of anesthesia.2013; 110(2): 175-82.

https://doi.org/10.1093/bja/aes447 PMid:23248093

11. Wareham AC, Morton RH, Meakin GH. Low quantal content of the end plate potential reduce safety factor for neuromuscular transmission in diaphragm of the newborn rat, $\mathrm{Br}$ JAnaesth. 1994;72: 205-9.

https://doi.org/10.1093/bja/72.2.205

PMid:8110574

12. Banieghbal B, Gouws M, Davies MR Respiratory pressure monitoring as an indirect method of intraabdominal pressure measurement in gastroschisis closure Eur J Pediatr Surg. 2006 ;16(2):79-83. https://doi.org/10.1055/s-2006-924051 PMid:16685611

13. Olesevich $\mathrm{M}$, Alexander $\mathrm{F}$ et al Gastroschisis revisited: role of intraoperative measurement of abdominal pressure journal of pediatric surgery.2005; 40:789-792.

https://doi.org/10.1016/j.jpedsurg.2005.01.043 PMid:15937815

14. Rizzo, A and C Davis, P and R Hamm, C and Powell, Randall, Intraoperative vesical pressure measurements as a guide in the closure of abdominal wall defects The American surgeon. 1996; 62:1926. 